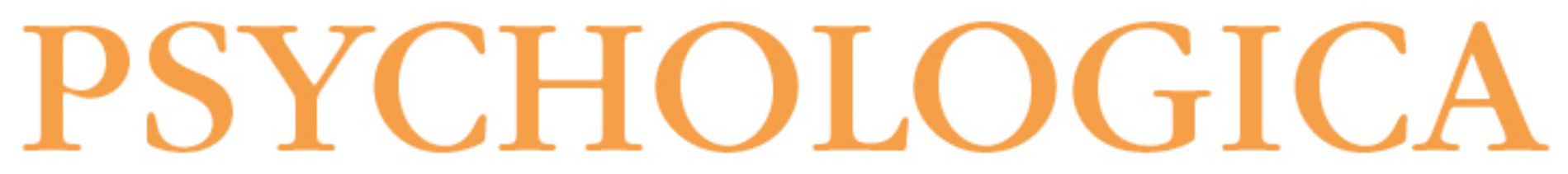

Se o coração pensasse, pararia? desenvolvimento de um instrumento de avaliação da inteligểncia emocional grupal

Autor(es): $\quad$ Correia, Ana Cármen; Dimas, Isabel Dórdio; Lourenço, Paulo Renato

Publicado por: Imprensa da Universidade de Coimbra

URL

persistente: URI:http://hdl.handle.net/10316.2/5612

Accessed : $\quad$ 26-Apr-2023 10:52:10

A navegação consulta e descarregamento dos títulos inseridos nas Bibliotecas Digitais UC Digitalis, UC Pombalina e UC Impactum, pressupõem a aceitação plena e sem reservas dos Termos e Condições de Uso destas Bibliotecas Digitais, disponíveis em https://digitalis.uc.pt/pt-pt/termos.

Conforme exposto nos referidos Termos e Condições de Uso, o descarregamento de títulos de acesso restrito requer uma licença válida de autorização devendo o utilizador aceder ao(s) documento(s) a partir de um endereço de IP da instituição detentora da supramencionada licença.

Ao utilizador é apenas permitido o descarregamento para uso pessoal, pelo que o emprego do(s) título(s) descarregado(s) para outro fim, designadamente comercial, carece de autorização do respetivo autor ou editor da obra.

Na medida em que todas as obras da UC Digitalis se encontram protegidas pelo Código do Direito de Autor e Direitos Conexos e demais legislação aplicável, toda a cópia, parcial ou total, deste documento, nos casos em que é legalmente admitida, deverá conter ou fazer-se acompanhar por este aviso. 


\section{NÚMERO 55}

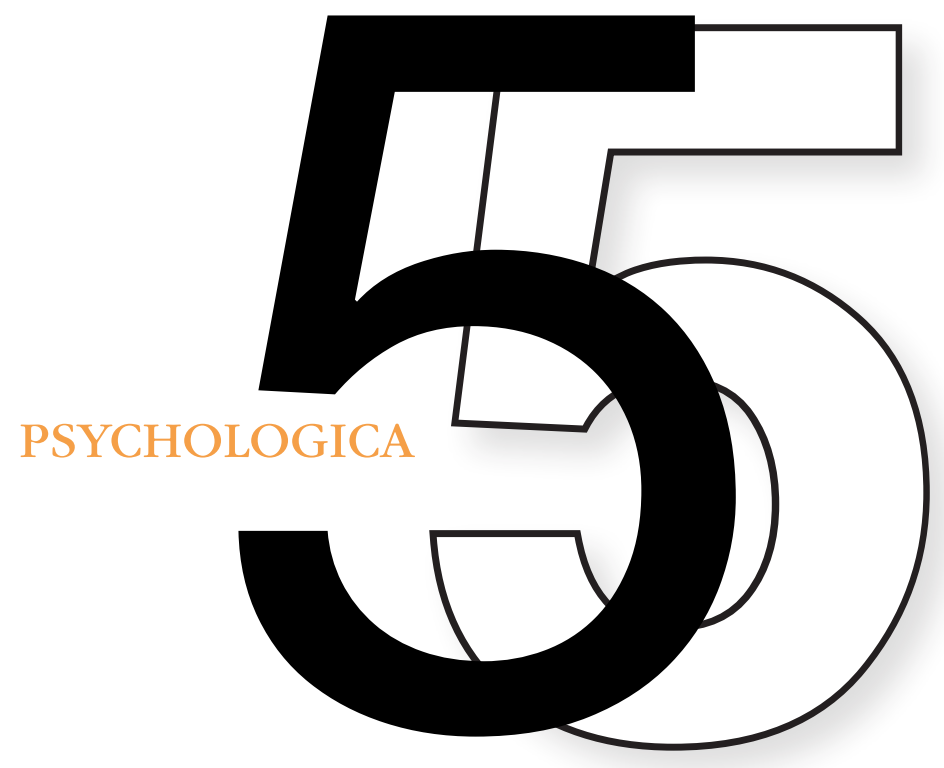

PSICOLOGIA DAS

ORGANIZAÇÕES

DO TRABALHO E DOS

RECURSOS HUMANOS 


\title{
Se o coração pensasse, pararia? - Desenvolvimento de um Instrumento de Avaliação da Inteligência Emocional Grupal
}

\author{
Ana Cármen Correia', Isabel Dórdio Dimas² \& Paulo Renato Lourenço’
}

O modelo de Inteligência Emocional Grupal de Druskat e Wolff (2001a; 2001b) apresenta seis dimensões caracterizadoras da Inteligência Emocional, situadas a três níveis de análise, e constituídas por normas que, teoricamente, despertam e regulam as emoções nos grupos/equipas. No presente estudo, foi adaptado para a língua portuguesa o Group Emotional Intelligence Questionnaire (Hamme, 2003), questionário ancorado no modelo referido e que comporta cinco dimensões (Regulação dos Membros sobre o Grupo, Auto-Consciência do Grupo, AutoRegulação do Grupo, Consciência Social do Grupo, e Competências Sociais do Grupo). Contando com uma amostra de 333 indivíduos pertencentes a 74 grupos, foi testada a validade de constructo do Questionário de Inteligência Emocional Grupal (QIEG), através de uma Análise em Componentes Principais (ACP). Os resultados evidenciaram a emergência de quatro dimensões interpretáveis, em vez das cinco previstas com base no instrumento original. As dimensões avaliadas no OIEG - Regulação dos Membros sobre o Grupo, Auto-Consciência do Grupo, Auto-Regulação do Grupo, e Consciência/Competências Sociais do Grupo - apresentaram valores de consistência interna satisfatórios, apontando para um bom nível de fiabilidade do instrumento.

PALAVRAS-CHAVE: Inteligência Emocional Grupal, grupos/equipas, instrumento de avaliação, análise em componentes principais.

\section{Introdução}

Como contraponto à visão tradicional que opõe seres racionais a criaturas eminentemente emocionais, a perspectiva dominante na actualidade defende que as emoções influenciam a avaliação inerente a processos que, por vezes, se julgam ser apenas baseados na razão. Elas ajudam o indivíduo, organizando o seu pensamento, guiando a sua atenção, e motivando o seu comportamento.

\footnotetext{
1 Faculdade de Psicologia e de Ciências da Educação da Universidade de Coimbra

2 Escola Superior de Tecnologia e Gestão de Águeda - Universidade de Aveiro - idimas@ua.pt
} 
Sob este prisma, as emoções podem ser definidas como respostas organizadas - envolvendo múltiplos subsistemas psicológicos (cognitivo, motivacional, fisiológico, experiencial) - a acontecimentos internos ou externos, que têm para a pessoa uma determinada valência, positiva ou negativa (Mayer \& Salovey, 1990).

Esta alteração no modo como a emoção passou a ser entendida surgiu, em grande medida, porque a Psicologia e outras ciências sociais redescobriram Charles Darwin (Salovey, 2006). Na sua obra A Expressão das Emoções nos Homens e nos Animais, Darwin (2006) chama a atenção para o facto de o nosso sistema emocional ser um sistema inteligente. Embora não tenha usado a expressão sistema inteligente, é isso que o autor descreve ao argumentar que o sistema emocional evoluiu, porque ajuda os seres vivos a sobreviver, guiando os comportamentos necessários para essa sobrevivência. Por exemplo, um sorriso de alegria assinala que, à partida, é seguro que alguém se aproxime; um esgar de tristeza significa que o indivíduo precisa de atenção. Assim, é este sistema inteligente que, ao fornecer informação sobre o estado emocional, comunica também conhecimento.

A popularização desta nova visão das emoções no seio da comunidade científica deve-se, em parte, aos estudos realizados no âmbito das neurociências, os quais sugerem que o sistema emocional e o sistema cognitivo estão em contacto próximo, comunicando constantemente. Damásio (1994) veio transmitir um novo impulso à ideia de que, no nosso cérebro, não há preto nem branco, mas, antes, cinzento. Ou seja, que cognição e emoção não são processos independentes - mas fortemente relacionados. $\mathrm{O}$ autor aduziu que não é possível decidir correctamente sem a intervenção das emoções, que o exercício eficaz das actividades cognitivas (e.g., gestão) exige o recurso à razão e à emoção.

Embora intrínsecas à natureza humana, as emoções foram durante muito tempo uma espécie de "parente pobre" da actividade organizacional e das investigações realizadas neste contexto (Cunha, Rego, Cunha \& Cardoso, 2003). Por um lado, porque durante décadas, a visão extremamente racional das organizações impediu o reconhecimento das emoções como um aspecto próprio da vida organizacional, em geral (De Dreu, West, Fisher \& MacCurtain, 2001), e do trabalho em grupo, em particular ${ }^{3}$ (Kelly \& Barsade, 2001). Por outro lado, os estados emocionais foram, tendencialmente, considerados fenómenos individuais, e como tal não acessíveis nem geríveis do ponto de vista da organização.

3 Acontece que um grande número de emoções humanas cresce e desenvolve-se a partir de interacções sociais, influenciando inevitavelmente a vida grupal (Barsade \& Gibson, 1998). 
Na verdade, só recentemente se pôde observar um crescendo de interesse pela matéria, muito embora diversas variáveis consideradas como centrais ao comportamento organizacional, tendo sido, por isso, amplamente estudadas, revelem uma evidente componente emocional ${ }^{4}$ (e.g., turnover, absentismo, motivação, mudança, conflitos). É provável que este novo estatuto conferido às emoções tenha resultado, em forte medida, de um reconhecimento dos estados emocionais como um tópico de investigação relevante (e.g., Briner, 1999; Fisher \& Ashkanasy, 2000; Svyantek \& Rahim, 2002), mas também da ascensão da Inteligência Emocional ao estatuto de relevante na gestão (Cunha et al., 2003).

As emoções detêm funções sociais importantes no trabalho em equipa, e a expressão de emoções, tanto positivas como negativas, e vividas/expressas com maior ou menor intensidade, não só nos informa sobre o funcionamento da equipa como, ao mesmo tempo, afecta os processos que decorrem no seu seio. Além disso, as emoções desencadeiam e guiam processos críticos na organização, tais como a gestão de conflitos e o desenvolvimento de ideias úteis e criativas, podendo potenciar a eficácia do trabalho colectivo (De Dreu, West, Fischer \& MacCurtain, 2001).

Segundo Druskat e Wolff (2001a, 2001b) e também Hamme (2003), saber como as emoções afectam o comportamento nos/dos grupos é, desta forma, útil para compreender e predizer comportamentos. De igual modo, a medição das competências para gerir as emoções é central para compreender os fenómenos a este nível. Druskat e Wolff (2001b) definem o conceito de Inteligência Emocional Grupal como um conjunto de normas grupais capazes de despertar e regular as emoções nos grupos. Na sua formulação, a Inteligência Emocional Grupal relaciona-se com o modo como os grupos "gerem" as emoções dos membros que os compõem, como regulam as emoções colectivas, e como interagem com outros grupos. Tendo por base o Modelo de Inteligência Emocional Grupal dos autores supracitados (Druskat \& Wolff, 2001a), bem como o instrumento desenvolvido por Hamme (2003), pretende-se, com a presente investigação, dotar investigadores e gestores de um instrumento capaz de aferir o funcionamento dos grupos/equipas, em termos da sua Inteligência Emocional Grupal, no contexto português. Mais especificamente, o principal objectivo do presente estudo traduz-se na adaptação e na análise das qualidades psicométricas do instrumento de avaliação da Inteligência Emocional Grupal de Hamme.

\footnotetext{
4 Deste modo, embora a investigação focada especificamente nas emoções em contextos organizacionais seja relativamente recente (Briner, 1999), o estudo das variáveis referidas indica que, implicitamente, a emoção foi sendo assumida a priori como parte integral e inseparável da vida corporativa.
} 


\section{Enquadramento conceptual}

\subsection{A Inteligência Emocional}

O conceito de Inteligência Emocional foi introduzido na literatura em 1990, por Mayer e Salovey, que o definem como a capacidade de o indivíduo "monitorizar não só os seus sentimentos e emoções, mas também os dos outros, de os diferenciar entre si, e de usar essa informação para guiar o pensamento e o comportamento"s (p.7). Esta definição inicial é, contudo, considerada, mais tarde, um pouco vaga, por enfatizar apenas a compreensão e a regulação das emoções, e negligenciar o facto de também se poder pensar com o auxílio delas. Assim, em 1999, Mayer e Salovey propuseram uma nova definição de Inteligência Emocional, a qual se refere à "capacidade de reconhecer os significados das emoções e das suas relações, e em raciocinar e resolver problemas com base nelas. A Inteligência Emocional abarca a capacidade de perceber as emoções, assimilar/integrar emoções e sentimentos, compreender o conteúdo ou informação dessas emoções, e saber geri-las"6 (p. 267).

O domínio da Inteligência Emocional foi também analisado sob outro prisma, envolvendo mais do que a capacidade de percepcionar, usar, compreender, e regular as emoções. As concepções derivadas incluem não só a emoção e a inteligência per se, mas também a motivação, traços não-disposicionais, e o funcionamento social, destacando-se, neste âmbito, Daniel Goleman. O autor popularizou o termo Inteligência Emocional, definindo-a como "a capacidade de reconhecer as próprias emoções e as dos outros, de se auto-motivar, e de as gerir adequadamente no contexto das suas relações" (Goleman, 1998, p. 317). No seu modelo mais recente de Inteligência Emocional (Goleman, 2001), o autor identifica quatro dimensões emocionais e sociais básicas: a Auto-consciência, que se refere à capacidade do indivíduo reconhecer as suas emoções; a Autoregulação, respeitante à capacidade de controlar emoções desagradáveis e em inibir a impulsividade emocional; a Consciência Social, que envolve a capacidade de compreender empaticamente os outros; e a Competência Social, que requer o saber gerir relacionamentos.

Importa notar que as várias conceptualizações partilham, logicamente, diferenças na visão que adoptam sobre o paradigma da Inteligência Emocional, mas que segundo Caputi, Chan e Ciarrochi (2000) tendem a convergir num ponto comum: todas elas procuram entender como os indivíduos usam as emoções, num esforço que visa predizer a eficácia pessoal, e aumentar a vantagem no dia-

\footnotetext{
5 A tradução é nossa.

6 A tradução é nossa.
} 
a-dia. Assume, desta forma, forte relevância, estudar a Inteligência Emocional nas organizações, em geral, e nos grupos, em particular. Com efeito, num contexto laboral marcado por metamorfoses massivas, consequência, nomeadamente, da inovação tecnológica, competitividade, e pressões de tempo, as qualificações pessoais e as competências de iniciativa, relacionamento interpessoal, auto-consciência e auto-regulação emocional posicionam-se como essenciais ao sucesso das organizações.

\subsection{A Inteligência Emocional Grupal}

\subsubsection{Definição de grupo/equipa e o papel das emoções}

Realidade incontornável nas organizações, os grupos/equipas assumem-se, actualmente, como a forma privilegiada de realizar o trabalho (Pinto, 2008). Com natureza formal ou informal e com duração temporária ou permanente, os grupos/equipas têm sido vistos pelas organizações como um factor estratégico que Ihes permite tomar vantagem competitiva e alcançar o sucesso organizacional7 (Dimas, 2007), acarretando também benefícios intra-psíquicos e emocionais para os colaboradores ${ }^{8}$ (De Dreu et al., 2001).

Importa clarificar, primeiramente, a noção de grupo/equipa que é adoptada no presente capítulo. Para que um conjunto de pessoas seja considerado um grupo/ equipa, é necessário que estejam presentes forças impulsoras de base, que se revelam necessárias e suficientes à sua emergência: percepção de interdependência entre os membros; percepção de, pelo menos, um alvo comum mobilizador; e relações entre as pessoas em função do alvo comum ${ }^{9}$. Os grupos são, desta forma, um sistema social, composto por um conjunto de elementos que interagem de uma forma interdependente, tendo em vista o alcance de um alvo comum (Dimas, 2007). Enquanto sistemas, os grupos/equipas estruturam-se em torno de dois subsistemas: o subsistema tarefa (referente ao conjunto de pessoas que trabalham e se articulam para a execução de uma tarefa) e o subsistema socioa-

7 Em muitas organizações, a unidade básica da estrutura de trabalho é o grupo/equipa em vez do indivíduo (Rousseau, Aubé \& Savoie, 2006).

8 Algumas razões para formar um grupo/equipa são a proximidade física, a rapidez de decisão, a partilha de conhecimento, a criação de espírito de equipa, ou a partilha de responsabilidades (Aslan, Ozata \& Mete, 2008).

9 Grupos e equipas serão no presente trabalho usados indistintamente, pese embora o debate existente à volta destes dois termos relativo à questão de se considerar grupo e equipa como remetendo para o mesmo fenómeno ou para entidades distintas (cf. Lourenço, 2002). 
fectivo (relativo ao conjunto de pessoas que trabalham procurando satisfazer as necessidades socioemocionais ${ }^{10}$ ) [Lourenço, 2002].

Embora esteja estabelecido que os grupos se edificam em torno das componentes supracitadas, a atenção dos investigadores tem estado sobretudo direccionada para a compreensão das questões da tarefa, sendo o papel das emoções secundarizado ou apenas implicitamente considerado (DeDreu et al, 2001; Kelly \& Barsade, 2001). Mas as emoções resultam do contexto social onde são manifestadas, influenciando esse mesmo contexto. E porque a existência de um grupo implica necessariamente a presença de relações sociais específicas entre os seus membros, as emoções constituem-se como parte dos processos grupais (De Dreu et al., 2001). A este nível, as emoções são partilhadas pelos membros através de processos como o contágio emocional, a comparação social, ou o modelamento vicariante (Barsade \& Gibson, 1998; Kelly \& Barsade, 2001), resultando num sentimento colectivo diferente da soma das emoções individuais.

Neste sentido, alguns investigadores (e.g., Barsade, 2002) têm chamado a atenção para a necessidade de estudar o fenómeno emocional, não apenas no nível individual, como tradicionalmente acontece, mas também no nível grupal. A importância de se estudar especificamente as emoções ao nível grupal está já patente nos estudos de Lewin e Festinger (s.d., cit. por De Dreu et al., 2001), que mostraram que os processos grupais não podem ser totalmente compreendidos quando a componente afectiva é ignorada. Efectivamente, as emoções jogam um papel preponderante em múltiplos processos grupais (e.g., tomada de decisão, comportamentos pró-sociais, motivação, negociação e resolução de conflitos, liderança, desempenho, e eficácia do grupo) pelo que a sua influência e contribuição deve ser ponderada quando se estuda e intervém nesses processos.

\subsubsection{A Inteligência Emocional Grupal}

Goleman, Boyatzis e Mckee (2002), no seu artigo The Emotional Reality of Teams, apresentam um exemplo de como a Inteligência Emocional Grupal pode influenciar o comportamento e o desempenho do grupo numa organização. A equipa de gestão de topo de uma determinada empresa industrial aceitou o desafio de procurar soluções para o facto de a empresa estar a perder competitividade. Contudo, as reuniões da equipa sucediam-se e nenhuma solução

\footnotetext{
10 Estes dois subsistemas, embora distinguíveis, são interactivos, interdependentes entre si, e interdependentes com a sua envolvente. Portanto, apenas considerando ambos e analisando a dinâmica das suas interrelações, se poderá compreender todo o sistema (Lourenço, 2002).
} 
era apresentada. O problema parecia estar relacionado com o facto de a equipa evitar tópicos sobre os quais os seus membros estavam em desacordo. Para evitar o conflito e terminar rapidamente a reunião, alguns membros chegavam, mesmo, a mostrar acordo em assuntos-chave, quando, na realidade, estavam em discordância. Entretanto, a empresa regredia cada vez mais na implementação de uma estratégia que se adivinhava crucial para garantir a sua viabilidade. Para aferir o que se estava a passar com o grupo, foi feita uma auditoria aos seus membros, tendo ficado claro que praticamente todos se sentiam incomodados pelos desacordos interpessoais, demonstrando baixos níveis de competência emocional, em particular no que tocava à gestão de conflitos. Os membros deste grupo desconheciam que a discussão aberta de ideias - em oposição aos ataques a quem manifesta visões alternativas - pode potenciar a tomada de decisão. Para os membros deste grupo, a tomada de consciência da sua incapacidade de lidar com as emoções e de as gerir de uma forma eficaz, foi fundamental para constatarem o que, como indivíduos, e como grupo, necessitavam de mudar.

De acordo com Goleman et al. (2002), somente quando os grupos enfrentam e analisam a sua realidade emocional colectiva - ou seja, quando os membros reconhecem o modo como funcionam e as situações dissonantes e desconfortáveis que enfrentam - é que podem, eventualmente, mudar. Os membros do grupo devem, desta forma, descobrir a fonte de descontentamento, que reside frequentemente em regras-base estabelecidas há muito tempo e profundamente enraizadas - as normas grupais.

A Inteligência Emocional parece, assim, não dever ser perspectivada apenas como uma competência individual, mas também como uma propriedade e competência grupal. Com efeito, embora tenha origem nos membros do grupo e, desta forma, no nível individual, ela pode apresentar-se como uma característica do colectivo. Isto porque apesar de a Inteligência Emocional variar de indivíduo para indivíduo, as interacções que se estabelecem entre os membros de um grupo, com o decorrer do tempo, podem promover qualidades caracterizadoras do grupo como um todo. Foram Druskat e Wolff (2001a, 2001b) que, primeiramente, alargaram o conceito de Inteligência Emocional à esfera grupal. A Inteligência Emocional Grupal resulta, de acordo com os autores, na capacidade de um grupo para desenvolver um conjunto de normas destinadas a gerir os processos emocionais, de forma a cultivar a confiança, a identidade do grupo e a eficácia grupal". Estas normas colectivas facilitam, por seu lado,

11 A Inteligência Emocional Grupal é vista, pelos autores, como uma analogia da Inteligência Emocional individual, sendo isomórfica nos seus efeitos (Ashkanasy \& Daus, 2002) ao nível, por exemplo, do desempenho. 
o desenvolvimento de cooperação e colaboração entre os membros do grupo, que em última instância pode conduzir a maior produtividade e criatividade, bem como a melhores decisões.

Deste modo, para um grupo ser emocionalmente inteligente, devem estar presentes as seguintes condições: 1) confiança mútua entre todos os membros, 2) sentido de pertença ao grupo por parte de todos os membros, 3) crença de que existe um efeito sinérgico no grupo, 4) capacidade de alcançar melhores resultados trabaIhando em conjunto, em vez de separados (Druskat \& Wolff, 2002). Importa ainda não esquecer que uma equipa com membros com elevada Inteligência Emocional não constitui necessariamente uma equipa emocionalmente inteligente. Para isso acontecer, deve existir uma atmosfera grupal (Druskat \& Wolff, 2001a, p. 82) que englobe a competência emocional (isto é, a capacidade para responder de modo construtivo em situações emocionalmente desconfortáveis) e que encare as emoções com um olhar positivo.

\subsubsection{O Modelo de Inteligência Emocional Grupal de Druskat e Wolff (2001a, 2001b)}

Druskat e Wolff (2001a, 2001b) criaram um Modelo de Inteligência Emocional Grupal (apresentado, resumidamente, no quadro 1), legível segundo três níveis de análise - individual, grupal e organizacional. Distribuidas por estes níveis, encontram-se seis dimensões - Consciência do Grupo sobre os Membros, Regulação do Grupo sobre os Membros, Auto-Consciência do Grupo, Auto-Regulação do Grupo, Consciência Social do Grupo, e Competências Sociais do Grupo -, que por sua vez se decompõem em onze normas - Tomada de Perspectiva, Compreensão Interpessoal, Confronto dos Membros que rompem as Normas, Comportamento Atencioso, Auto-avaliação da Equipa, Procura de Feedback, Criação de Recursos para trabalhar com a emoção, Criação de um Ambiente Positivo, Resolução Pró-activa dos problemas, Compreensão Organizacional e Criação de relações externas -, capazes de despertar consciência sobre as emoções e de as regular. Em última instância, estas normas possuem a função de reforçar os sentimentos de confiança, identidade, e eficácia grupal.

Subjacente à elaboração deste modelo, está a premissa de que a Inteligência Emocional Grupal é mais complexa que a Inteligência Emocional individual, já que a equipa interage em mais níveis. O sujeito emocionalmente inteligente é capaz de tomar consciência sobre as suas emoções e de as regular (Goleman, 1995). Já o grupo com elevada Inteligência Emocional deve estar atento e regular as emoções não só de cada um dos seus membros (nível individual), mas também as emoções do grupo (nível grupal), e ainda as de outros grupos/indivíduos com os quais se relaciona (nível organizacional). 
Quadro 1. Modelo de Inteligência Emocional Grupal (Druskat \& Wolff, 2001a, 2001b)

\begin{tabular}{|c|c|c|}
\hline $\begin{array}{l}\qquad \text { Individual } \\
\text { (Sentimento de apoio e } \\
\text { aceitação social, e ajuda no } \\
\text { equilibrio entre as necessidades } \\
\text { grupais e individuais). }\end{array}$ & $\begin{array}{l}\quad \text { Grupal } \\
\text { (Consciência e regulação } \\
\text { de estados emocionais, } \\
\text { preferências e recursos } \\
\text { na esfera grupal). }\end{array}$ & $\begin{array}{l}\quad \text { Organizacional } \\
\text { (Consciência e regulação dos } \\
\text { sentimentos e necessidades } \\
\text { de indivíduos/grupos externos } \\
\text { mas relevantes). }\end{array}$ \\
\hline $\begin{array}{l}\text { Consciência do Grupo sobre os } \\
\text { Membros }\end{array}$ & Auto-Consciência do Grupo & Consciência Social do Grupo \\
\hline $\begin{array}{l}\text { Tomada de Perspectiva } \\
\text { 1. Decorre da conversação, e } \\
\text { é exibida como a vontade de } \\
\text { considerar determinado assunto } \\
\text { sob o ponto de vista da outra } \\
\text { pessoa. } \\
\text { 2. Beneficia o grupo de duas } \\
\text { formas: facilita a assimilação } \\
\text { de informação importante e, } \\
\text { ao sentir que a sua perspectiva } \\
\text { é ouvida e considerada, um } \\
\text { membro tende a confiar e a } \\
\text { identificar-se mais com o seu } \\
\text { grupo e suas decisões, resultando } \\
\text { num maior envolvimento no } \\
\text { trabalho em equipa. }\end{array}$ & $\begin{array}{l}\text { Auto-avaliação da Equipa } \\
\text { 1. Capacidade de um grupo para } \\
\text { se avaliar a si mesmo, incluindo } \\
\text { os estados emocionais, forças e } \\
\text { fraquezas. } \\
\text { 2. Manifesta-se através da } \\
\text { recolha de informação sobre } \\
\text { outros grupos, e consequente } \\
\text { comparação com o próprio, } \\
\text { sendo que a informação } \\
\text { emergente é usada para } \\
\text { definir aspectos a manter } \\
\text { e/ou a mudar. }\end{array}$ & \multirow{2}{*}{$\begin{array}{l}\text { Compreensão Organizacional } \\
\text { 1. Implica entender o sistema } \\
\text { sociopolítico no qual o grupo } \\
\text { se insere, ou seja, apreender a } \\
\text { cultura e o porquê das tomadas } \\
\text { de decisão na empresa. } \\
\text { 2. Tem como objectivo último } \\
\text { servir a equipa quando ela } \\
\text { necessita de recursos externos, } \\
\text { ao permitir que os membros } \\
\text { sejam capazes de argumentar } \\
\text { tendo por base as condições } \\
\text { organizacionais, e assim } \\
\text { aumentar as hipóteses de } \\
\text { garantir esses recursos. } \\
\text { 3. Reconhecimento das } \\
\text { expectativas e necessidades } \\
\text { de outros grupos na } \\
\text { organização - consciência } \\
\text { intergrupal- possibilitando } \\
\text { a realocação de recursos e o } \\
\text { estabelecimento de relações } \\
\text { positivas entre os diferentes } \\
\text { membros. }\end{array}$} \\
\hline $\begin{array}{l}\text { Compreensão Interpessoal } \\
\text { 1. Compreensão dos } \\
\text { sentimentos, interesses, } \\
\text { preocupações, pontos fracos e } \\
\text { pontos fortes dos membros. } \\
\text { 2. Permite aos indivíduos } \\
\text { interpretar e lidar com as } \\
\text { expressões emocionais e } \\
\text { comportamentos não-verbais. }\end{array}$ & $\begin{array}{l}\text { Procura de feedback } \\
\text { 1. Solicitação de opiniões } \\
\text { externas (e.g., clientes) sobre o } \\
\text { desempenho do grupo, com o } \\
\text { intuito de trabalhar para a sua } \\
\text { evolução contínua. } \\
\text { 2. Benchmarking das práticas } \\
\text { usuais. }\end{array}$ & \\
\hline $\begin{array}{l}\text { Regulação do Grupo sobre os } \\
\text { Membros }\end{array}$ & Auto-Regulação do Grupo & Competências Sociais do Grupo \\
\hline $\begin{array}{l}\text { Confronto dos membros que } \\
\text { rompem as normas } \\
\text { 1. Existência de regras } \\
\text { de conduta, em que o } \\
\text { incumprimento de uma } \\
\text { ou mais dessas regras pelo } \\
\text { membro do grupo deve ser } \\
\text { referenciado. }\end{array}$ & $\begin{array}{l}\text { Criação de recursos para } \\
\text { trabalhar com a emoção } \\
\text { 1. Aceitação das emoções como } \\
\text { parte integrante da vida grupal. } \\
\text { 2. Criação de vocabulário } \\
\text { intra-grupo para expressar } \\
\text { determinado estado emocional. } \\
\text { 3. Aceitação das emoções dos } \\
\text { membros do grupo. }\end{array}$ & $\begin{array}{l}\text { Criação de relações externas } \\
\text { 1. Prestação de ajuda a outras } \\
\text { equipas. } \\
\text { 2. Convidar eventuais } \\
\text { interessados de outras equipas } \\
\text { a assistir a reuniões do grupo. } \\
\text { 3. Criação de relações saudáveis } \\
\text { com agentes externos. } \\
\text { 4. Obtenção de apoio externo } \\
\text { e garantia de recursos. }\end{array}$ \\
\hline \multirow{2}{*}{$\begin{array}{l}\text { Comportamento Atencioso } \\
\text { 1. Comunicação de afecto, apreço } \\
\text { e respeito - o grupo valoriza a } \\
\text { presença e a contribuição de } \\
\text { cada indivíduo. } \\
\text { 2. Entreajuda entre os membros: } \\
\text { suporte emocional, capacidade } \\
\text { de escuta, e flexibilidade. } \\
\text { 3. Aumenta o sentimento de } \\
\text { segurança, coesão e satisfação } \\
\text { individuais. }\end{array}$} & $\begin{array}{l}\text { Criação de um ambiente positivo } \\
\text { 1. Optimismo. } \\
\text { 2. Foco na resolução das tarefas, } \\
\text { não culpabilizando } \\
\text { 3. Reforço da ideia de que o } \\
\text { grupo consegue cumprir os } \\
\text { desafios. }\end{array}$ & \\
\hline & $\begin{array}{l}\text { Resolução Pro-activa de } \\
\text { problemas } \\
\text { 1. Iniciativa para prever } \\
\text { problemas antes que } \\
\text { eles aconteçam. } \\
\text { 2. Controlo imediato/activo } \\
\text { sobre um problema que ocorra. }\end{array}$ & \\
\hline
\end{tabular}


Os autores sugerem que o modo como o grupo lida com as emoções do indivíduo, do grupo, e da organização é um elemento crítico para a construção destas normas (Druskat \& Wolff, 2001b).

Embora a última década tenha sido marcada por pesquisas relativas ao conceito de Inteligência Emocional Grupal (Druskat, 1996; Druskat \& Wolff, 2001a, 2001b), sua medição (Hamme, 2003; Jordan et al., 2002) e influência no domínio organizacional (Buckley et al., 2003; Cherniss \& Goleman, 2001; Yost \& Tucker, 2000), alguns críticos põem em causa a existência deste constructo. Como justificação, referem que, apesar de a ênfase ser direccionada ao grupo, é o indivíduo quem assume a ligação crítica para a Inteligência Emocional Grupal. Assim, ela aparenta ser nada mais do que a combinação do nível de Inteligência Emocional de cada membro do grupo, e por isso reside ainda no plano individual.

Mas definir o grupo enquanto sistema social pressupõe o reconhecimento da existência de um todo que emerge em resultado das inter-relações mútuas que se estabelecem entre as suas unidades. Pressupõe ainda encarar o grupo como uma realidade, uma entidade viva que transcende e não pode ser explicada pela experiência individual (Lourenço. 2002). Deste modo, o grupo é ao mesmo tempo mais, menos, e diferente do que a soma das suas partes; as partes são menos, eventualmente mais, e de qualquer forma diferentes do que seriam fora do grupo ${ }^{12}$ (Dimas, 2007). Assim, e na linha dos investigadores que estudam a Inteligência Emocional no contexto dos grupos, assumimos, no presente trabalho, que a Inteligência Emocional Grupal existe, de facto como um constructo teórico, e face às considerações até agora tecidas, o passo seguinte consiste em analisar a gestão (consciente e deliberada) que o grupo faz das emoções. Para isso, assume particular relevância o desenvolvimento de um instrumento válido capaz de medir a Inteligência Emocional Grupal'3.

\footnotetext{
12 Por um lado, o grupo pode ser enriquecimento, na medida em que as ligações estabelecidas entre as diferentes componentes fazem emergir uma entidade - o todo - maior do que a soma das contribuições individuais. Por outro, o conjunto de restrições, constrangimentos inerentes às relações grupais conduzem a que as contribuições individuais se diluam no sistema. Toda a associação implica constrangimentos, quer eles sejam exercidos pelas partes interdependentes (umas sobre as outras), pelas partes sobre o todo, ou ainda pelo todo sobre as partes - o grupo é, desta forma, e também, empobrecimento (Dimas, 2007).

13 Quando se diz que um instrumento é válido, estamos a assumir uma posição ontológica de que o atributo que está a ser medido existe e afecta o resultado do procedimento de medida" (Borboom, Mellenberg \& Van Heerden, 2004, p.1063). Assim, a Inteligência Emocional Grupal é o referencial para os resultados do questionário. Se estes são reais, o referencial também deve ser real (Pasquali, 2007).
} 


\section{Metodologia}

\subsection{Amostra}

A amostra do presente estudo é constituída por equipas de trabalho de diferentes organizações dos sectores industrial e dos serviços. A opção por este tipo de grupos baseou-se, em primeiro lugar, no facto de se enquadrarem na concepção de grupo de trabalho que adoptamos - um sistema social, constituido por indivíduos que interagem regularmente, de uma forma interdependente, tendo em vista o alcance de um alvo comum mobilizador. Em segundo lugar, a selecção deste tipo de grupos foi influenciada pelo facto de se tratar de grupos "naturais" (por contraste com os laboratoriais), a operar em contexto organizacional.

A amostra inicial foi constituída através do método de amostragem por conveniência ou acessibilidade (Hill \& Hill, 2001) ${ }^{14}$, sendo composta por 342 sujeitos. Foram eliminados nove $(2,6 \%)$ por conterem um número de itens não respondido igual ou superior a $10 \%$ em cada uma das escalas constantes no questionário (Bryman \& Cramer, 2004). Após este procedimento inicial, a amostra ficou com um total de 333 participantes, membros de 74 equipas de trabalho, de 14 empresas de áreas diferenciadas.

\subsection{Instrumento: Group Emotional Intelligence Questionnaire (GEIQ15)}

\subsubsection{Estrutura e conteúdo}

À escassez de estudos empíricos relativos à Inteligência Emocional Grupal, a que já aludimos no enquadramento teórico, não é alheio o facto de serem poucos os instrumentos de avaliação existentes passíveis de medir este constructo. $\mathrm{O}$ Group Emotional Intelligence Questionnaire (GEIO), desenvolvido por Hamme (2003), foi o instrumento de avaliação por nós escolhido para adaptar para a língua portuguesa por quatro razões fundamentais. Em primeiro lugar, tratase do único questionário validado que se destina verdadeiramente a avaliar a Inteligência Emocional ao nível grupal. Isto porque outros instrumentos, embora almejem avaliar a Inteligência Emocional no grupo, consideram para o efeito a soma da Inteligência Emocional de cada membro, individual e independen-

\footnotetext{
14 Este método assenta na utilização, por parte do investigador, de uma rede de relações interpessoais, de natureza formal ou informal, que facilitam o acesso à amostra (os casos escolhidos são facilmente disponíveis) (Hill \& Hill, 2001).

15 O desenvolvimento da versão portuguesa do GEIQQ foi por nós designada de Questionário de Inteligência Emocional Grupal (QIEG).
} 
temente. E, portanto, residem ainda ao nível da Inteligência Emocional individual ${ }^{16}$. Em segundo lugar, este instrumento foi concebido para ser utilizado em contexto organizacional e em diferentes tipos de organizações. Por outro lado, é um questionário que se fundamenta num modelo de Inteligência Emocional Grupal - o modelo de Inteligência Emocional Grupal de Druskat e Wolff (2001a; 2001b) - que tem recebido alguma atenção na literatura. Por último, na sua versão final, apresenta boas qualidades psicométricas.

A autora começou por construir um total de 196 itens, com base nas dimensões e normas do modelo teórico. Apesar de, no modelo publicado, Druskat e Wolff (2001a) terem abandonado a norma Orientação Embaixadora e combinado a Compreensão Intergrupal e Compreensão Organizacional numa só, Hamme (2003) optou por incluir as treze normas iniciais associadas às seis dimensões. Os itens foram apresentados aos autores do modelo teórico que, após avaliarem a compreensibilidade de cada um e a relevância para a norma e dimensão à qual pertenciam, eliminaram aqueles que revelavam falta de clareza, ambiguidade, ou dificuldade na sua formulação, tendo ficado o instrumento com um total de 118 itens.

De seguida, Hamme (op cit.) conduziu uma análise da consistência interna das normas contendo os itens correspondentes. Das treze, apenas oito revelaram um valor satisfatório (igual ou superior a .70), tendo sido eliminadas as cinco com valores inferiores, e respectivos itens.

Só depois a autora realizou uma Análise Factorial Exploratória (AFE) com rotação oblimin para averiguar a emergência das seis dimensões contendo os 78 itens exemplificativos das oito normas. Foram extraídos seis factores, sendo que cinco apresentaram valores de alpha superiores a .70, detendo quatro ou mais itens, e explicando $40 \%$ da variância total. Como o sexto factor, Consciência do Grupo sobre os Membros, apresentava um valor de alpha igual a .47 e integrava apenas três itens (segundo a autora, inconsistentes com a teoria) foi abandonado.

O último passo consistiu numa AFE em tudo semelhante à anterior, exceptuando o facto de ter sido realizada só com as cinco dimensões consideradas. Os itens que não pontuavam no factor de origem foram rejeitados. Perante um novo cálculo da consistência interna de cada factor, a autora obteve valores iguais ou superiores a .70, demonstrando serem consistentes com as cinco dimensões do Modelo de

16 É o caso, por exemplo, do Workgroup Emotional Intelligence Profile (WEIP), desenvolvido por Jordan, Ashkanasy, Härtel e Hooper (2002), e construído especialmente para medir a Inteligência Emocional dos indivíduos em equipas de trabalho. 
Inteligência Emocional Grupal, e retendo itens com saturações superiores a .40, e comunalidades entre .41 e .78 .

Na sua versão definitiva, o GEIQ integra 29 itens. Os respondentes devem indicar o grau em que cada afirmação reflecte o comportamento da sua equipa, numa escala Likert de 7 pontos, onde 1 = Discordo Totalmente, e 7 = Concordo Totalmente (op.cit).

\subsubsection{Processo de adaptação do Group Emotional Intelligence Questionnaire (GEIO) para a língua portuguesa}

Como o presente trabalho envolve um instrumento que, à luz das suas características e propriedades se considera adequado para os propósitos da investigação, foram utilizados os itens da escala original, com a respectiva adaptação - modificação em termos de conteúdo e formulação - tendo em conta as circunstâncias linguísticas ${ }^{17}$.

O desenvolvimento do Questionário de Inteligência Emocional Grupal (QIEG) - cumpriu o protocolo que a literatura da especialidade estabelece como prática adequada para a adaptação de um instrumento de avaliação (Bryman \& Cramer, 2004; Hill \& Hill, 2000). Neste sentido, os procedimentos técnicos consagraram quatro momentos sequenciados: tradução do questionário, retroversão independente, reunião de peritos, e aplicação do questionário a um grupo-piloto.

O processo teve início com a tradução directa da versão inglesa do questionário para a língua portuguesa, concretizada por dois peritos com formação base em psicologia, competências no domínio da metodologia da investigação científica em psicologia, e proficiências linguísticas em inglês. Uma vez averiguada a concordância entre as traduções, o texto foi entregue para retroversão a uma tradutora com formação base em tradução especializada de inglês. Verificou-se que as versões mostraram ser semelhantes, por isso o questionário foi considerado adequado e capaz de transitar à fase seguinte. Através de uma reunião com um painel de cinco peritos ${ }^{18}$, avaliou-se a validade de conteúdo, garantindo que a versão traduzida dos itens constituía um equivalente linguístico e prag-

\footnotetext{
17 Torna-se claro que é essencial manter o mais possivel o sentido original dos itens, pois o objectivo é o de conseguir, no maior número possível de itens, uma tradução literal. Mas nos casos em que isso não seja possível, ou em que uma tradução literal pode distorcer o sentido do item (caso de expressões idiomáticas, por exemplo) ou, ainda, em que a tradução literal resulta num item ambíguo, estranho ou difícil de compreender, deve-se efectuar as modificações que se afigurem necessárias (Moreira, 2004).

18 Neste âmbito, entenda-se por peritos um conjunto de investigadores com formação base em Psicologia das Organizações e do Trabalho.
} 
mático dos itens originais, que existia adequação e representatividade dos itens relativamente ao constructo teórico, e que as categorias de resposta se revestiam de adequação. Na generalidade, os investigadores consideraram os itens claros e adequados ao seu objectivo, mas surgiu a necessidade de se alterarem alguns elementos relativos à estrutura e conteúdo do questionário. Destaca-se, ao nível da estrutura, a modificação das instruções (no sentido de melhorar a adequabilidade, precisão e clareza), e ainda a alteração de quase todos os itens para a forma positiva ${ }^{19}$, mantendo-se, no entanto, alguns na forma original constituindo, porém, itens inversos ${ }^{20}$. Já ao nível do conteúdo, importa assinalar que, após a tradução, se constatou que os itens 21 (Se alguém no nosso grupo/ equipa parece triste, respeitamos a sua privacidade e não perguntamos o que se passa) e 24 (Se alguém no nosso grupo/equipa está triste, perguntamos-Ihe o que se passa) eram muito próximos em termos de conteúdo, pelo que se optou pela retirada do item 21, dada a presença da conjunção "e", o que é desaconselhável e pode condicionar a validade das respostas. Deste modo, o QIEG resultou num total de 28 itens pertencentes a cinco dimensões/factores: Regulação do Grupo sobre os Membros, Auto-Consciência do Grupo, Auto-Regulação do Grupo, Consciência Social do Grupo, e Competências Sociais do Grupo. A verificação da adequação do questionário (clareza e compreensibilidade dos itens, tipo de respostas/escala de medida, estrutura e layout) foi efectuada numa amostra de 10 sujeitos pertencentes à população em estudo - o grupo-piloto (Field, 2000). Após a aplicação dos questionários, realizou-se uma reflexão falada sobre o instrumento, da qual resultou a constatação de que todos os itens foram adequadamente compreendidos, não tendo emergido qualquer dúvida. Assim, a versão final adaptada do OIEG ficou composta pelo mesmo número de itens abrangidos na reunião de peritos.

\subsubsection{Estudos de dimensionalidade e de fiabilidade}

\subsubsection{Procedimentos estatisticos}

Na medida em que o propósito do presente estudo consagra a identificação da estrutura dimensional da versão portuguesa do Group Emotional Intelligence Questionnaire (GEIQ), concebido noutro contexto organizacional, a técnica de

19 A opção de construir os itens na forma afirmativa justificou-se pelas seguintes razões: é desaconseIhável o uso de itens na negativa; os itens na forma negativa aumentam a confusão aquando da escolha da opção de resposta que melhor define o grupo; a insistência no termo "não" torna o questionário aparentemente negativista/pessimista.

20 Esta decisão primou pela tentativa de diminuir o efeito da aquiescência, não esquecendo que os resultados invertidos serão utilizados tanto no cálculo do total como no da correlação dos itens com esse total (Moreira, 2004). 
análise em componentes principais, cujo objectivo geral consiste em sumariar a informação contida nas variáveis (e.g., itens) num novo conjunto mais reduzido de dimensões compósitas (e.g., factores), com uma perda mínima de informação, constitui a opção mais adequada.

Esta perspectiva, porque não estabelece restrições apriorísticas relativamente à estimação do número de componentes que podem ser extraídos, reveste-se de utilidade sempre que o objectivo da aplicação da técnica consagra a identificação de constructos hipotéticos num conjunto de variáveis (Field, 2000). Por se tratar de uma escala por nós adaptada e, consequentemente, sem qualquer historial de utilizações anteriores, a condução de uma análise em componentes principais (ACP) afigurou-se como a opção mais adequada.

De forma a garantir a estabilidade da solução emergente da análise noutras amostras, é fundamental que a amostra utilizada seja suficientemente grande, sendo, de um modo geral, sugerido como condição mínima de utilização desta técnica a existência de pelo menos cinco sujeitos por item avaliado, e não menos de 100 indivíduos por análise (Bryman \& Cramer, 2004). A esta escala responderam 333 sujeitos (rácio de 11.9/1), cumprindo-se, desta forma, os requisitos necessários para a sua realização.

\subsubsection{Resultados}

Os 28 itens que compõem o questionário em análise foram submetidos a uma ACP com rotação ortogonal varimax ${ }^{21}$, e extracção livre de factores. Quer a medida da adequação da amostragem de Kaiser $(K M O=.87)$ quer o teste de esfericidade de Bartlett $[$ x2 (378) = 3495.98, p<0.001] apresentaram valores indicativos da boa adequação da análise factorial aos dados observados.

A solução revelou-se, contudo, pouco satisfatória quer em termos estatísticos quer em termos de interpretabilidade. Os dois critérios mais utilizados para a determinação do número de factores a extrair - o critério de Kaiser (1960) e o teste scree de Cattell (1966) - não se revelaram concordantes, uma vez que enquanto o primeiro sugeria a extracção de sete factores, o segundo apontava para a retenção de somente quatro.

\footnotetext{
21 A rotação ortogonal (varimax) foi a nossa opção pelo facto de melhorar a interpretabilidade da solução inicial e, consequentemente, promover a sua utilidade científica (Tabachnick \& Fidell, 2001) Esta técnica procura simplificar a complexidade dos factores através da maximização da variância dos pesos factoriais em cada um deles. Ao extremar a dispersão desses pesos, a interpretação de cada factor torna-se mais fácil, uma vez que destaca as variáveis (itens) que mais se correlacionam com esse factor. A técnica procede ainda a uma redistribuição da variância entre os factores extraídos com o intuito de os equiparar em termos de importância (Miguel, 2006).
} 
Os sete factores encontrados (cf. quadro 2) explicavam uma variância total de $60.3 \%$ e incluíam os seguintes itens: o primeiro factor, responsável por $27.5 \%$ da variância, integrava três itens da dimensão Auto-Regulação do Grupo (itens 2, 9, e 17), três itens da dimensão Consciência Social do Grupo (itens 3, 10, e 18), e um item da dimensão Auto-Consciência do Grupo (item 16); o segundo factor, responsável por $9.9 \%$ da variância total, integrava três itens relativos à dimensão Competências Sociais do Grupo (itens 15, 25, e 27), dois itens da Consciência Social do Grupo (itens 24 e 28), e um item da Auto-Regulação do Grupo (item 23); o terceiro factor explicava $6.1 \%$ da variância total, e agrupava todos os itens destinados a avaliar a dimensão Regulação do Grupo sobre os Membros (itens 6, 7, e 13), e um item da dimensão Competências Sociais do Grupo (item 11); o quarto factor detinha $4.5 \%$ da variância total, integrando três itens da dimensão Auto-Consciência do Grupo (itens 20, 21, e 22) e um item da dimensão Competências Sociais do Grupo (item 19); o quinto factor comportou-se de modo semelhante ao factor dois ao integrar itens das dimensões Competências Sociais do Grupo (item 12) e Consciência Social do Grupo (itens 4 e 26), e explicava 4.3\% da variância total; o sexto e o sétimo factor apresentavam-se ambos como factores espúrios, sendo cada um responsável por apenas $4 \%$ da variância total - o sexto factor integrava três itens sem interligação aparente entre si (itens 1, 5, e 8, que avaliavam, respectivamente, a Regulação dos Membros sobre o Grupo, as Competências Sociais do Grupo, e a Auto-Consciência do Grupo); e o sétimo factor englobava apenas um item destinado a avaliar a Auto-Consciência do Grupo (item 14).

Analisando em detalhe os sete factores, apenas quatro se afiguravam, na realidade, interpretáveis à luz da teoria subjacente, razão pela qual foram testadas outras estruturas factoriais ${ }^{22}$, conforme descrevemos em seguida.

22 Cada estrutura, incluindo a primeira, foi pautada pela observação de vários critérios, designadamente do critério de Kaiser (1966), do teste scree de Cattell (1966), da percentagem de variância total explicada, das comunalidades e saturações dos itens e ainda da consistência interna das soluções sugeridas. Paralelamente a estes critérios de cariz estatístico, foram também considerados aspectos de natureza teórica e conceptual, nomeadamente a adequação da estrutura factorial à perspectiva teórica subjacente e o conteúdo de cada um dos itens e sua importância na medição do constructo teórico em causa (Dimas, 2007). 
Quadro 2. Saturações Factoriais (S) e Comunalidades $\left(h^{2}\right)$

Item $n^{\circ}$

2.Nas nossas reuniões, tentamos reservar algum tempo para falar das emoções sentidas pelos membros do grupo/equipa (por exemplo: frustração, contentamento). 3.Os membros do nosso grupo/ equipa podem facilmente explicar como são tomadas as decisões nesta organização 9.Os membros têm o cuidado de não deixar que os seus sentimentos interfiram nas discussões do grupo/equipa. 10.0 nosso grupo/equipa encaixa-se bem no sistema organizacional.

16.Avaliamos o nosso grupo/ equipa e o seu desempenho.

17. No nosso grupo/equipa, reservamos tempo para os membros discutirem as suas emoções (por exemplo: frustração, contentamento).

18.Para o nosso grupo/equipa, são claras as razões pelas quais se tomam grande parte das decisões na organização.

15.Consideramos uma prioridade que o nosso grupo/ equipa tenha boas relações com outros grupos/equipas da organização.

23.Se alguém no nosso grupo/ equipa está triste, perguntamos-lhe o que se passa.

24.É clara a forma como o nosso trabalho tem impacto nos resultados da organização.

25.Normalmente, temos tempo para ajudar outros grupos/ equipas.

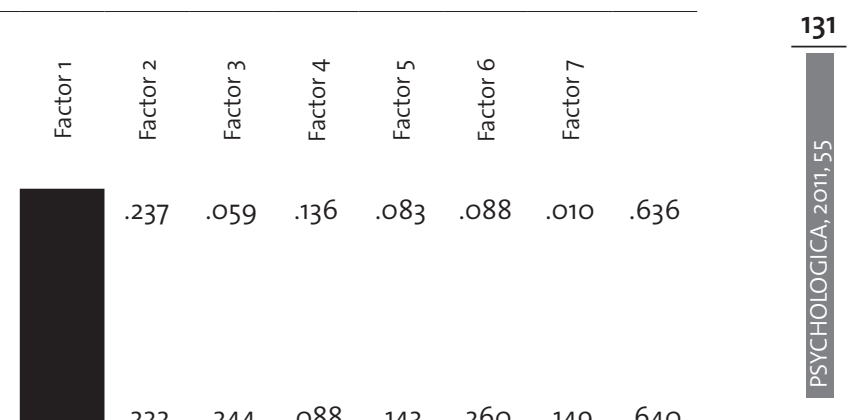

$\begin{array}{lllllll}.222 & .244 & .088 & .143 & .260 & .149 & .640\end{array}$

$\begin{array}{lllllll}-.128 & -.176 & -.050 & -.128 & -.160 & -.601 & .393\end{array}$

$\begin{array}{lllllll}.257 & .269 & -.007 & .168 & .041 & .201 & .543\end{array}$

$\begin{array}{lllllll}.325 & .074 & .368 & -.018 & .167 & .140 & .540\end{array}$

$\begin{array}{lllllll}.138 & .060 & .316 & .003 & -.021 & .018 & .654\end{array}$

$\begin{array}{lllllll}.225 & .310 & .381 & .039 & .220 & .045 & .559\end{array}$

.393

$\begin{array}{llllll}.032 & -.065 & -.049 & .053 & .057 & .587\end{array}$

$\begin{array}{llllll}-.064 & .009 & .034 & -.062 & .032 & .603\end{array}$

$\begin{array}{llllll}.024 & .200 & .401 & .001 & -.154 & .631\end{array}$ 
Item $n^{\circ}$

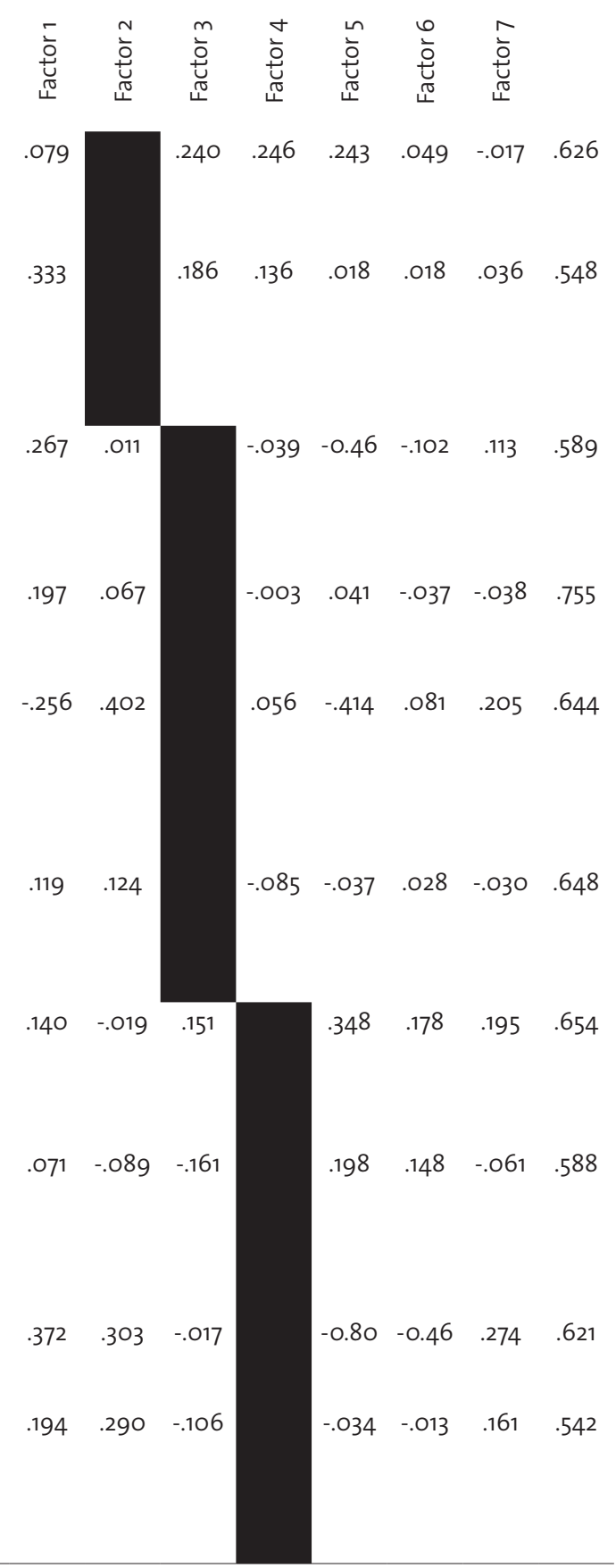

27. Os outros grupos/equipas sabem que estamos disponíveis para os ajudar e aconselhar.

28. No nosso grupo/equipa compreendemos a forma como as nossas tarefas se enquadram no funcionamento geral da organização.

6.Apenas a opinião de alguns membros tem peso nas decisões tomadas pelo grupo/ equipa ( $R$ ).

7.Alguns membros do grupo/ equipa tratam outros membros de forma pouco correcta (R).

11.Ajudar outros grupos/equipas atrasa frequentemente o nosso ritmo de trabalho, pelo que tentamos não nos envolver nos seus problemas (R).

13. Existe falta de respeito na forma como alguns membros do grupo/equipa tratam outros membros (R).

19. Costumamos utilizar como recurso a informação proveniente de outros grupos/ equipas da organização.

20.Comparamo-nos frequentemente com outros grupos/equipas para termos uma ideia do nosso desempenho.

21.Dedicamos tempo a avaliar o nosso próprio trabalho.

22.Os membros do grupo/ equipa recebem feedback dos outros membros sobre o seu desempenho. 
Item $n^{\circ}$

S $\quad h^{2}$

\begin{tabular}{|c|c|c|c|c|c|c|c|c|}
\hline & 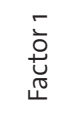 & 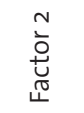 & 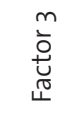 & 市 & 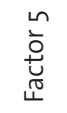 & 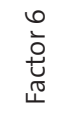 & 产 & \\
\hline $\begin{array}{l}\text { 4. Temos muita informação } \\
\text { sobre outros grupos/equipas da } \\
\text { nossa organização. }\end{array}$ & .360 & .157 & .102 & .109 & & .287 & .268 & .527 \\
\hline $\begin{array}{l}\text { 12. Os elementos do nosso } \\
\text { grupo/equipa procuram junto } \\
\text { de outros grupos obter apoio } \\
\text { para o nosso trabalho. }\end{array}$ & .143 & .127 & -.019 & .089 & & -.079 & .392 & 619 \\
\hline $\begin{array}{l}\text { 26.Os elementos do nosso } \\
\text { grupo/equipa conseguem } \\
\text { descrever as necessidades que } \\
\text { os restantes grupos/equipas da } \\
\text { organização têm. }\end{array}$ & .036 & .341 & -.167 & .371 & & .132 & -.125 & .642 \\
\hline $\begin{array}{l}\text { 1.Quando algum } \\
\text { membro se comporta } \\
\text { de forma inapropriada, } \\
\text { comentamos entre nós o seu } \\
\text { comportamento, embora não o } \\
\text { confrontemos directamente (R). }\end{array}$ & -.202 & -.035 & -.047 & -.300 & .093. & & .236 & .545 \\
\hline $\begin{array}{l}\text { 5.Se outro grupo/equipa da } \\
\text { organização precisa da nossa } \\
\text { ajuda, tentamos ajudar. }\end{array}$ & .217 & .489 & .164 & -.132 & .038 & & .142 & .611 \\
\hline $\begin{array}{l}\text { 8.Conhecer a forma como os } \\
\text { outros (indivíduos ou outros } \\
\text { grupos) avaliam o desempenho } \\
\text { do grupo/equipa é uma } \\
\text { prioridade. }\end{array}$ & .127 & -.043 & -.268 & .108 & .122 & & 200 & .642 \\
\hline $\begin{array}{l}\text { 14.O grupo é capaz de mudar } \\
\text { em função do feedback que } \\
\text { recebe de outros (indivíduos ou } \\
\text { grupos). }\end{array}$ & .116 & .015 & .023 & .175 & .111 & .049 & .776 & .662 \\
\hline
\end{tabular}

Numa segunda análise em componentes principais ${ }^{23}$ excluiu-se, desde início, o item 9 ("Os membros têm o cuidado de não deixar que os seus sentimentos interfiram nas discussões do grupo/equipa"), devido à sua baixa comunalidade

23 Quer a medida da adequação da amostragem de Kaiser $(K M O=.82)$ quer o teste de esfericidade de Bartlett $\left[\chi^{2}(105)=1695.45, p<0.001\right]$ suportam a utilização da análise factorial nesta matriz de correlações. 
$\left(h^{2}=.39\right)$. Além disso, e apesar de os argumentos estatísticos apontarem para a retenção de quatro factore ${ }^{24}$, a análise foi forçada a cinco com o objectivo de averiguar o comportamento de todos os itens perante a estrutura factorial que era prevista teoricamente. Os resultados demonstraram que alguns deles apresentavam saturações salientes em mais do que um factor $(r \geq .4)$, ou seja, eram factorialmente complexos, pelo que o segundo passo implicou a sua exclusão. Desta forma, foram eliminados, sequencialmente, o item $4(.42$ no segundo factor, e .52 no quinto), o item 5 (.47 no primeiro factor e .49 no segundo), o item 8 (.48 no segundo factor, e .44 no quinto), o item 18 (.47 no segundo factor, e .42 no quarto), o item 26 (.39 no primeiro factor, e .46 no quarto), o item $1^{25}$ (-.52 no segundo factor, e -.40 no quarto), e o item 16 (.49 no segundo factor, e .38 no quarto). Após estas análises sequenciais o QIEG ficou, no final, com 20 itens.

Como só quatro factores se mostraram realmente interpretáveis ${ }^{26}$, submetemos os 20 itens a uma terceira ACP com rotação ortogonal (varimax) e forçada a quatro factores ${ }^{27}$. Foram eliminados, sequencialmente, os itens que a presentaram comunalidades inferiores a .40 (Stevens, 1986), assim como os itens que saturavam noutra dimensão que não a sua, sem que teoricamente se afigurasse possível explicar esse facto, e que baixavam a consistência interna da dimensão. Como resultado, optámos por uma estrutura composta por quatro factores, integrando 14 itens, que explicam 62.84\% da variância (quadro 3).

\footnotetext{
24 Note-se que o segundo e o quinto factores apresentam resultados idênticos integrando itens de duas dimensões maioritárias, a Consciência Social do Grupo e as Competências Sociais do Grupo.

25 A disparidade das saturações verificadas neste item deveu-se a um erro topográfico, que consistiu na omissão de parte do conteúdo do item, ficando resumido a "Quando algum membro se comporta de forma inapropriada, comentamos entre nós o seu comportamento, directamente". O facto de termos considerado o item até esta fase justifica-se pela detecção tardia desse erro, que ocorreu só nesta fase, após a aplicação do instrumento.

26 No quinto factor, saturaram apenas o item 12 ("Os membros do nosso grupo/equipa procuram junto de outros grupos obter apoio para o nosso trabalho") e o item 14 ["O grupo/equipa é capaz de mudar em função do feedback que recebe de outros (indivíduos/grupos)]. Verificámos que enquanto o primeiro pertence à dimensão Competências Sociais do Grupo, o segundo insere-se na Regulação do Grupo sobre os Membros, situadas a diferentes níveis de análise. Analisando também o seu conteúdo não conseguimos, paralelamente, encontrar qualquer interpretação teórica para a emergência deste factor.

27 Tanto a medida da adequação da amostragem de Kaiser $(K M O=.85)$ como o teste de esfericidade de Bartlett $\left[\chi^{2}(171)=2225.58, p<0.001\right]$ suportam a utilização da análise factorial nesta matriz de correlações.
} 
Quadro 3. Saturações factoriais $(S)$, comunalidades $\left(h^{2}\right)$, valores próprios e total de variância

\begin{tabular}{l} 
Item \\
\hline 24. É clara a forma como o nosso \\
trabalho tem impacto nos resultados da \\
organização.
\end{tabular}

27. Os outros grupos/equipas sabem que estamos disponíveis para os ajudar e aconselhar.

28. No nosso grupo/equipa compreendemos a forma como as nossas tarefas se enquadram no funcionamento geral da organização.

25. Normalmente, temos tempo para ajudar outros grupos/equipas.

15. Consideramos uma prioridade que o nosso grupo/equipa tenha boas relações com outros grupos/equipas da organização.

7. Alguns membros do grupo/equipa tratam outros membros de forma pouco correcta. (R)

13. Existe falta de respeito na forma como alguns membros do grupo/equipa tratam outros membros. (R)

6. Apenas a opinião de alguns membros tem peso nas decisões tomadas pelo grupo/equipa. (R)

19. Costumamos utilizar como recurso a informação proveniente de outros grupos/ equipas da organização.

20. Comparamo-nos frequentemente com outros grupos/equipas para termos uma ideia do nosso desempenho.

21. Dedicamos tempo a avaliar o nosso próprio trabalho.

22. Os membros do grupo/equipa recebem feedback dos outros membros sobre o seu desempenho.

17. No nosso grupo/equipa, reservamos tempo para os membros discutirem as suas emoções (por exemplo: frustração, contentamento).

2. Nas nossas reuniões, tentamos reservar algum tempo para falar das emoções sentidas pelos membros do grupo/equipa (por exemplo: frustração, contentamento).

\begin{tabular}{lcccc}
\hline Valor próprio & 3.517 & 2.450 & 2.715 & 1,691 \\
Variância Explicada (\%) & $30.91 \%$ & $15.26 \%$ & $9.78 \%$ & $6.84 \%$ \\
\hline
\end{tabular}


O primeiro factor tem um valor próprio de 3.517 e explica 30.91\% da variância total. Foi-Ihe atribuída a designação Consciência/Competências Sociais do Grupo pelo facto de integrar dois itens construidos com o fim de medir a Consciência Social (itens 24 e 28) e três com o fim de medir as Competências Sociais (itens 15, 25, e 27) ${ }^{28}$. O segundo factor, denominado Regulação do Grupo sobre os Membros, integra três itens destinados a medir esta dimensão (itens 6,7 e 13), assumindo um valor próprio de 2.450 e explicando $15.26 \%$ da variância ${ }^{29}$.

O terceiro factor adquire um valor próprio de 2.715 , e é responsável por $9.78 \%$ da variância total. Assume-se como a Auto-Consciência do Grupo, integrando quatro itens construídos com o objectivo de a avaliar (itens 19, 20, 21 e 22) ) $^{30}$. Embora o item 19 ("Costumamos utilizar como recurso a informação proveniente de outros grupos/ equipas da organização") pertença, originalmente, à dimensão Competências Sociais do Grupo, a opção de o manter no presente factor deveu-se ao facto de apresentar um peso factorial de .66, e a sua análise de conteúdo revelar proximidade com os restantes itens e com o que encerra a dimensão Auto-Consciência do Grupo. O quarto e último factor tem um valor próprio de 1.691 e explica $6.84 \%$ da variância total. Integra dois itens construídos com o fim de medir a capacidade de o grupo se auto-regular, gerindo estados emocionais e criando respostas desejáveis (itens 2 e 17$)^{31}$ - por isso, foi nomeado Auto-Regulação do Grupo.

Todos os itens retidos apresentam comunalidades satisfatórias e saturações superiores a .40 .

28 Do conjunto de itens que saturou inicialmente neste factor, procedeu-se à exclusão do item 23 ("Se alguém do nosso grupo/equipa está triste, perguntamos-Ihe o que se passa"). Apesar do seu valor de saturação ser de .64, ele pertence, na origem, à dimensão Auto-Regulação do Grupo, e o seu conteúdo não se coaduna com o conteúdo dos outros itens nem com o factor em causa. Por outro lado, optámos pela exclusão do item 12 ("Os membros do nosso grupolequipa procuram junto de outros grupos obter apoio para o nosso trabalho"), que embora se enquadre no factor, apresentava uma comunalidade muito baixa $\left(h^{2}=.30\right)$.

29 Optou-se por eliminar o item 11 ("Ajudar outros grupos/equipas atrasa frequentemente o nosso ritmo de trabalho, pelo que tentamos não nos envolver nos seus problemas") pois, para além de não pertencer ao factor em causa - já que o seu conteúdo é referente ao nível organizacional - uma análise da consistência interna do factor revela a subida considerável do alpha no caso da exclusão deste item (de .74 para .78).

30 Eliminámos o item 14 ["O grupo/equipa é capaz de mudar em função do feedback que recebe de outros (indivíduos/grupos)"], uma vez que saturou numa dimensão que não a sua, e baixava a consistência interna da mesma.

31 Apesar de quatro itens terem saturado neste factor, dois deles - o item 3 ("Os membros do nosso grupolequipa podem facilmente explicar como são tomadas as decisões nesta organização") e o item 10 ("O nosso grupo/equipa encaixa-se bem no sistema organizacional") - foram eliminados por, teoricamente, pertencerem à dimensão Consciência Social do Grupo. Supomos que a razão pela qual o item 3 tenha saturado neste factor (.64) terá sido por se situar logo a seguir ao item 2, que integra este quarto factor. Por outro lado, o item 10 leva-nos a crer que tenha surgido alguma dificuldade ao nível da sua compreensão, uma vez que o próprio se revelou problemático no acto de adaptação do OIEG. 
A avaliação da fiabilidade, efectuada através do alpha de Cronbach, apontou para resultados razoáveis ${ }^{32}$ nas quatro dimensões - a dimensão Consciência/ Competências Sociais do Grupo obteve uma consistência interna de .78, a dimensão Regulação do Grupo sobre os Membros de .70, a dimensão Auto-Consciência do Grupo de .78, e a dimensão Auto-Regulação do Grupo de .80.

Por último, todos os itens possuem uma correlação moderada com a respectiva dimensão, excepto o item 7 cuja correlação se considera elevada33 (Quadro 4).

Quadro 4. Valores do alpha de Cronbach e correlações.

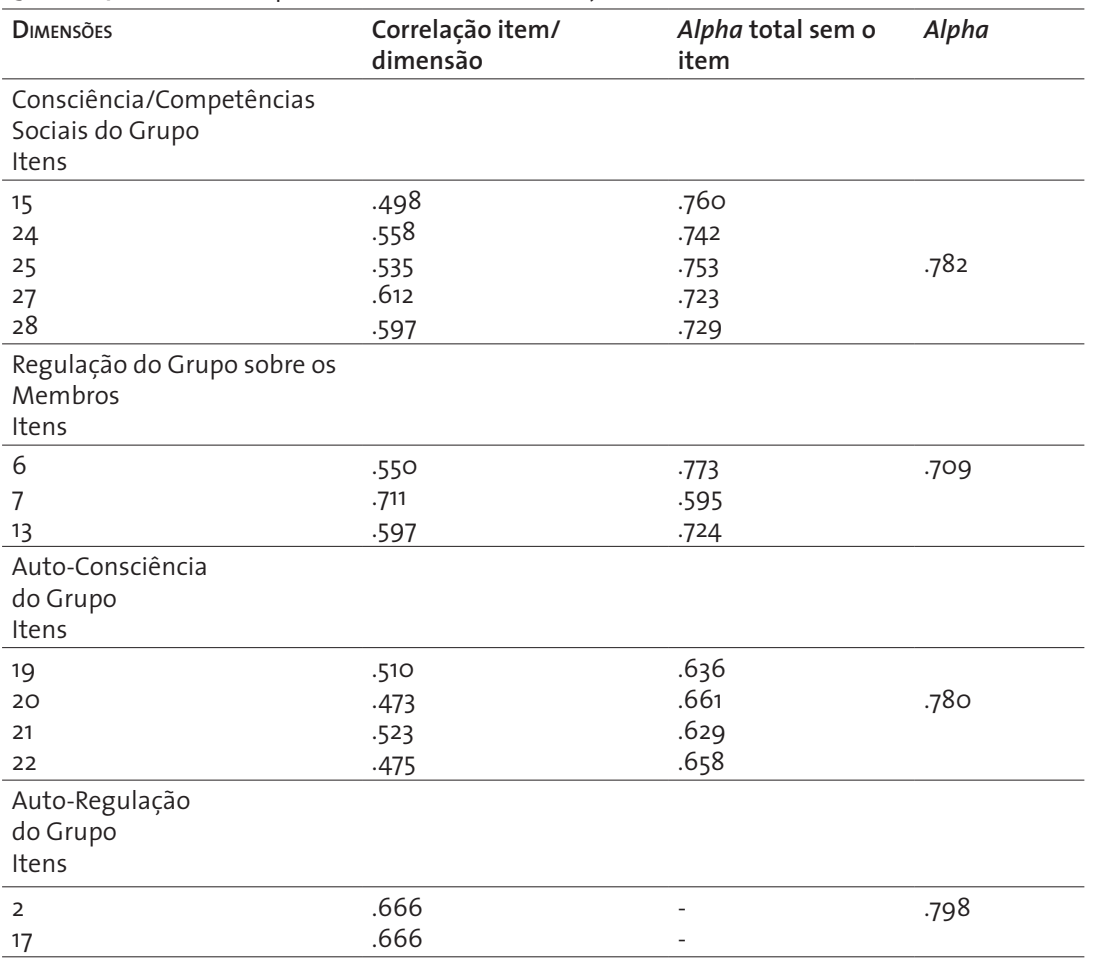

32 Pestana e Gageiro (2005) consideram que um valor de alpha superior a .9 indica uma consistência interna muito boa, entre .8 e .9 boa, entre .7 e .8 razoável, entre .6 e .7 fraca, e um valor de alpha inferior a 6 é considerado inadmissível.

33 Para a avaliação dos coeficientes de correlação, considera-se muito baixa uma correlação inferior a .19, baixa entre .20 e .39 , moderada entre .40 e .69 , elevada entre .70 e .89 , e muito elevada uma correlação acima de .90 (Bryman \& Cramer, 2004). 


\section{Discussão}

A presente secção tem como objectivo a realização de uma reflexão acerca dos resultados relativos aos estudos de dimensionalidade e de fiabilidade da versão portuguesa do Group Emotional Intelligence Questionnaire (GEIQ). Procuraremos, por isso, salientar alguns dos aspectos mais relevantes que decorrem dos referidos estudos.

De acordo com o Modelo de Inteligência Emocional Grupal em que nos ancoramos, e em função dos resultados obtidos na aplicação da versão original do instrumento (Hamme, 2003), prevíamos que emergissem cinco grandes factores, correspondentes às dimensões da Inteligência Emocional Grupal captadas pelo GEIO. Além disso, seria desejável que os itens saturassem na dimensão a que conceptualmente foram associados.

Uma das primeiras conclusões que se pode retirar diz respeito ao número de factores que foram extraídos e que, conforme descrito, não é convergente com o número teoricamente esperado. A autora do instrumento agrupa os 29 itens em cinco factores independentes: Regulação do Grupo sobre os Membros (4 itens), Auto-Consciência do Grupo (6 itens), Auto-Regulação do Grupo ( 5 itens), Consciência Social do Grupo (7 itens) e Competências Sociais do Grupo (7 itens). Ora, na nossa análise extraímos somente quatro. Como julgamos ter deixado claro aquando da apresentação dos resultados, tal facto terá ficado a dever-se, fundamentalmente, à junção dos itens da dimensão Consciência Social do Grupo com os itens da dimensão Competências Sociais do Grupo (cf. Factor I). Desde a primeira solução factorial emergente, que os itens de ambas as dimensões saturam substancialmente num só factor - além disso, não só apresentam saturações moderadas nesse factor (acima de .49) como o valor de alpha deste último é considerado bom $(\alpha=.78)$.

Por outro lado, quando olhamos a descrição conceptual de cada dimensão (Druskat \& Wolff, 2001b), encontramos pontos em comum: ambas pertencem ao mesmo nível de análise, o nível organizacional; ambas se revelam interdependentes e indissociáveis, já que estar consciente dos problemas/expectativas organizacionais e intergrupais, apesar de vital, é insuficiente para mobilizar os recursos necessários à eficácia - um grupo/equipa deve também possuir competências para desenvolver relacionamentos que ajudem a conseguir esses recursos.

Questionamo-nos, assim, se será útil, no plano das implicações práticas destes resultados, distinguir estas duas dimensões, ao invés de uni-las numa só. Possivelmente, além de análises da estrutura interna, é necessário realizar estudos de validação externa dos resultados nos factores (por exemplo, determinando a magnitude da sua relação com um conjunto teoricamente seleccionado de variáveis critério).

Uma segunda diferença importante entre o estudo original e os resultados por nós encontrados reporta-se ao Factor IV (Auto-Regulação do Grupo), originalmente 
medido por quatro itens (itens 2, 9, 17, e 23). Na nossa análise, ele contempla apenas dois desses quatro itens (designadamente, o item 2 e o item 17).

Todavia, apesar destas inegáveis diferenças, existem importantes pontos de convergência entre os resultados da presente análise e os obtidos na versão original. Os mais evidentes verificam-se no Factor II e, em menor grau, no Factor III.

O Factor II, Regulação do Grupo sobre os Membros, inclui exactamente os mesmos itens que na versão original Ihe pertenciam (itens 6, 7, e 13), acrescido o facto de terem obtido uma boa saturação neste factor (cf. Quadro II).

O Factor III, Auto-Consciência do Grupo, engloba três dos seis itens originalmente construídos para medir esta dimensão (itens 20, 21, e 22). Considerámos, porém, que seria benéfico manter neste factor o item 19 ("Costumamos utilizar como recursos a informação proveniente de outros grupos/equipas da organização") que, apesar de ter sido construído para medir a dimensão Competências Sociais do Grupo, satura significativamente nesta (.87). Esta excepção justifica-se por razões de carácter estatístico, mas sobretudo teórico, pois uma análise do seu conteúdo revelou semelhanças com os outros itens e com a própria dimensão. Com efeito, a Auto-Consciência do Grupo implica a sua auto-avaliação, manifestada usualmente pela recolha de informação sobre outros grupos (feedback) e a subsequente comparação com o próprio (Druskat \& Wolff, 2001b).

A apreciação da consistência interna dos factores do QIEG, analisada através do alpha de Cronbach, indica-nos que todos os coeficientes de fidelidade se encontram muito próximos de .8o. Portanto, cremos ser legítimo afirmar que o processo de adaptação do instrumento se reveste de êxito e que os factores do OIEG apontam no sentido de medirem as respectivas dimensões do constructo de uma forma viável.

Seria igualmente legítimo deduzir que se os mesmos itens agrupados nos mesmos factores revelam valores de consistência interna tendencialmente similares, então é porque o QIEG e o GEIQ convergem no conjunto de dimensões latentes que estão subjacentes nos itens assim replicados. À excepção do Factor I (Consciência/Competências Sociais), que integra duas dimensões inicialmente consideradas distintas, e do item 19 ("Costumamos utilizar como recurso a informação proveniente de outro grupos/ equipas da organização"), que está incluído numa dimensão diferente, os restantes itens por nós considerados enquadram-se nas mesmas dimensões que o instrumento norte-americano. Como tal, os resultados relativos à equivalência conceptual entre as duas versões do questionário integram-se não por completo, mas em grande parte.

Consideramos, ainda, que o facto de alguns itens não terem pontuado o suficiente num só factor para merecerem nele a sua inclusão - e que por isso foram eliminados - permitiu tornar o instrumento mais refinado e parcimonioso. 


\section{Conclusão}

A nossa investigação teve na sua origem a necessidade de medir o constructo Inteligência Emocional ao nível dos grupos/equipas de trabalho de organizações portuguesas. Neste sentido, procedeu-se à adaptação de um instrumento já criado para o efeito no contexto norte-americano, o Group Emotional Intelligence Questionnaire (GEIO), que reveste a vantagem de se ancorar no modelo teórico de Inteligência Emocional Grupal mais citado na literatura (Druskat \& Wolff, 2001a; 2001b).

O instrumento de medida adaptado, que denominámos Questionário de Inteligência Emocional Grupal (OIEG), revelou, com base no estudo que realizámos, possuir bons níveis de validade e fiabilidade. Em resultado de critérios, quer de natureza estatística quer teórica, chegámos a uma estrutura composta por quatro dimensões. Tendo presente que, neste estudo, utilizámos uma metodologia tipicamente exploratória, a estrutura que apresentamos, assim como o número de factores considerados, devem ser vistos como hipóteses que futuras investigações devem procurar validar. De qualquer forma, sob o ponto de vista conceptual, a análise concorre para suportar parte do modelo teórico de Druskat e Wolff (2001a; 2001b) que Hamme (2003) utilizou para o desenvolvimento dos itens. Este dado, se vier a ser replicado, abona em favor da validade de constructo do OIEG como medida da Inteligência Emocional Grupal.

Uma escala de avaliação da Inteligência Emocional Grupal válida e consistente, cuja pontuação resulte do contributo de todos os membros, poderá fornecer uma medida escrita das características grupais, com itens direccionados ao nível grupal ao invés do individual. Além disso, ultrapassará as dificuldades para diferenciar a percepção individual do próprio comportamento do grupo. Ainda, investigadores e consultores poderão identificar a componente emocional no trabalho em grupo, e perceber em que medida contribui para indicadores organizacionais, como o desempenho e a eficácia.

Conhecendo as competências associadas à Inteligência Emocional Grupal, as organizações podem também seleccionar colaboradores com disposições emocionais apropriadas, especialmente se vão integrar um grupo/equipa de trabalho.

Não negando a relevância e interesse dos resultados encontrados, há algumas limitações que importa referir. Uma primeira limitação diz respeito ao facto de a dimensão Auto-Regulação do Grupo incluir apenas dois itens. Se é verdade que somente os dois itens se comportaram como o previsto, também podemos dizer com propriedade que, logicamente, são eles quem define o factor. Nestas circunstâncias, a consulta da literatura referente à análise factorial facilmente nos mostrará que um factor definido no máximo por duas variáveis, dificilmente pode vir a ser replicado numa amostra independente. Sendo assim, sugerimos, 
para melhorar o instrumento, a construção de novos itens que permitam avaliar esta dimensão ou a realização de um novo estudo com todos os itens originais, com o fim de aferir de que forma se comportam numa amostra diferenciada.

A outra limitação relaciona-se com o facto de o número de itens cotados directa e inversamente não ser idêntico. Como tal, o efeito da aquiescência pode ter-se feito sentir nos resultados. Aquando do processo de selecção dos itens para a versão definitiva, é necessário o cuidado de assegurar que a versão final tenha igual número de itens com cotação directa e cotação inversa, e que a aquiescência não terá efeito nos resultados, pois a sua influência sobre os itens positivos (aumentar o resultado total da escala) será anulada pelos efeitos nos itens negativos (diminuir o resultado total). Como é óbvio, isto pressupõe que o efeito da aquiescência se exerça no mesmo grau sobre todos os itens, o que não é garantido. No entanto, mesmo que o efeito não seja eliminado, deverá pelo menos ser fortemente reduzido.

As considerações que acabámos de tecer têm implicações metodológicas e teóricas relevantes para a condução de novas investigações acerca da composição factorial deste instrumento. É com elas que encerramos este artigo, na esperança que pesquisas futuras a aprofundem.

\section{Bibliografia}

Ashkanasy, N., \& Daus, C. (2002). Emotion in the workplace: The new challenge for managers. Academy of Management Executive, 16, 76-86.

Aslan, S., Ozäta, M., \& Mete, M. (2008). The investigation of effects of group emotional intelligence on team effectiveness. Humanity \& Social Sciences Journal, 3(2), 104-115 .

Barsade, S. (2002). The ripple effect: Emotional contagion and its influence on group behavior. Administrative Science Quarterly, 47, 644-675.

Barsade, S., \& Gibson, D. (1998). Group Emotion: A view from top and bottom. Research on Managing Groups and Teams, 1, 81-102.

Borsboom, D., Mellenbergh, J., \& Van Heerden, J. (2004). The concept of validity. Psychological Review, 111(4), 1061-1071.

Briner, R. (1999). The neglect and importance of emotions at work. European Journal of Work and Organizational Psychology, 8(3), 323-346.

Bryman, A., \& Cramer, D. (2004). Análise dos dados em ciências sociais: Introdução às técnicas utilizando o SPSS. Oeiras: Celta.

Buckley, M., Ammeter, A., Prati, C., Douglas, C., \& Ferris, G. (2003). Emotional intelligence, leadership effectiveness, and team outcomes. International Journal of Organizational Analysis, 11(1), 21-40.

Caputy, P., Chan, A., \& Ciarrochi, J., (2000). A critical evaluation of the emotional intelligence concept. Personality and Individual Differences, 34, 1477-1490. 
Cherniss, C., \& Goleman, D. (2001). The Emotionally Intelligent Workplace: How to select for, measure, and improve El in individuals, groups and organizations. San Francisco, California: Jossey Bass.

Ciarrochi, J., \& Mayer, J. (2006). Clarifying concepts related to emotional intelligence: A proposed glossary. In J. Ciarrochi, J. Forgas, \& J. Mayer (Eds), Emotional Intelligence in Everyday Life, ( $2^{\text {nd }}$ ed.). New York: Psychological Press.

Cunha, M., Cardoso, C., Cunha, R., \& Rego, A. (2003). Manual de Comportamento Organizacional e Gestão. Lisboa: Editora Rh.

Damásio, A. (1994). O erro de Descartes. Lisboa: Europa-América.

Darwin, C. (2006). A expressão das moções nos homens e nos animais. Lisboa: Relógio D’ Água.

De Dreu, C., West, M., Fischer, A., \& MacCurtain, S. (2001). Origins and consequences of emotions in organizational teams. In P. Payne, \& C. Cooper (Eds.), Emotions at Work (pp.199-216). London: John Wiley \& Sons.

Dimas, I. (2007). (Re)pensar o conflito intragrupal: Níveis de desenvolvimento e eficácia. Dissertação de Doutoramento em Psicologia, Faculdade de Psicologia e de Ciências da Educação da Universidade de Coimbra.

Druskat, V., \& Wolff, S. (2001a). Building the emotional intelligence of groups. Harvard Business Review, 79(3), 81-90.

Druskat, V., \& Wolff, S. (2001b). Group emotional competence and its influence on group effectiveness. In C. Cherniss, \& D. Goleman (Eds.), The Emotionally Intelligent Workplace (pp.132-155). San Francisco, California: Jossey-Bass.

Druskat, V., \& Wolff, S. (2002). Emotional intelligence as the basis of leadership emergence in self-managing teams. Leadership Quarterly, 13(5), 505-522.

Field, A. (2000). Discovering Statistics using SPSS for Windows. London: Sage Publications.

Fisher, C., \& Ashkanasy, M. (2000). The emerging role of emotions in worklife: An introduction. Journal of Organizational Behavior, 21, 123-129.

Goleman, D. (1995). Emotional Intelligence. New York: Bantam Dell.

Goleman, D. (1998). Working with Emotional Intelligence. New York: Bantam Dell.

Goleman, D. (2001). Emotional Intelligence: Issues in paradigm building. In C. Cherniss \& D. Goleman (Eds.), The Emotionally Intelligent Workplace (pp.13-28). San Francisco: Jossey Bass.

Goleman, D., Boyatzis, R., \& Mckee, A. (2002). The emotional reality of teams. Journal of Organizational Excellence, 21(2), 55-65.

Hamme, C. (2003). Group emotional intelligence: The research and development of an assessment instrument. Dissertation Abstracts International, 64, 09B, 4663.

Hill, A., \& Hill, M. (2000). Investigação por Questionário. Lisboa: Edições Sílabo.

Jordan, P., Ashkanasy, N., Härtel, C., \& Hooper, G. (2002). Workgroup El scale development and relationship to team process effectiveness and goal focus. HRM Review, 12(2), 195-214.

Kelly, J., \& Barsade, S. (2001). Mood and emotions in small groups and work teams. Organizational Behavior and Human Decisions Processes, 86(1), 99-130.

Lourenço, P. R. (2002). Concepções e dimensões da eficácia grupal: desempenho e niveis de desenvolvimento. Dissertação de Doutoramento não publicada. Faculdade de Psicologia e Ciências da Educação da Universidade de Coimbra.

Mayer, J., \& Salovey, P. (1990). Emotional Intelligence. Imagination, Cognition, and Personality, 9, 185-211. Miguel, J. P. (2006). Inventário de interesses profissionais de Amesterdão: Adaptação e validação no ensino superior. Dissertação de Mestrado em Psicologia da Orientação Escolar e Vocacional, Faculdade de Psicologia e Ciências da Educação da Universidade de Coimbra. 
Moreira, J. M. (2004). Questionários: Teoria e prática. Coimbra: Almedina. Psicologia: Teoria e Pesquisa, 23, 99-107.

Pasquali, L. (2007). Validade dos testes psicológicos: Será possível reencontrar o caminho? Psicologia: Teoria e Pesquisa, 23, 99-107.

Pestana, M. H., \& Gageiro, J. (2005). Análise de dados para ciências sociais: A complementaridade de SPSS ( 4 a ed.). Lisboa: Sílabo.

Pinto, E. (2008). Emoções na vida grupal: Porque os grupos também sentem. Dissertação de Mestrado em Psicologia das Organizações e do Trabalho, Faculdade de Psicologia e Ciências da Educação da Universidade de Coimbra.

Rousseau, V., Aubé, C., \& Savoie, A. (2006). Teamwork Behaviors. Small Group Research, 37 (5), 540-570.

Salovey, P. (2006). Emotional Intelligence. The Annual Bulletin of Knowledge management society of Japan, VI, 1-10. Acedido a 15 de Outubro de 2009, através de: $h t t p: / / k m s$. jpn.org/annual-e.html

Stevens, J. (1986). Applied multivariate statistics for the social sciences. New York: Lawrence Erlbaum.

Svyantek, D., \& Rahim, M. (2002). Links between emotional intelligence and behavior in organizations: Findings from empirical studies. The International Journal of Organizational Analysis, 10(4), 299-301.

Tabachnick, B., \& Fidell, L. (2001). Using Multivariate Statistics. New York: Harper Collins.

Yang, J., \& Mussholder, K. (2004). Decoupling task and relationship conflict: The role of intragroup emotional processing, Journal of Organizational Behavior, 25, 589-605.

Yost, C., \& Tucker, M. (2000). Are effective teams more emotional intelligent? Confirming the importance of effective communication in teams. Delta Phi Epsilon Journal, 42(1), 101-109

\section{If the heart thought, would he stop? Development of a group emotional intelligence scale}

The model of Group Emotional Intelligence by Druskat and Wolff (2001a; 2001b) presents six dimensions which describe emotional intelligence, distributed through three analysis levels and formed by norms that, theoretically, arouse and regulate emotions in groups/teams. In this study, the Group Emotional Intelligence Questionnaire (Hamme, 2003, has been adapted to Portuguese, which has its basis on the model referred and that contains five dimensions (Group Regulation of Members, Group Self-Awareness, Group Self-Regulation, and Group Social Awareness/Skill). Based on a sample of 333 individuals belonging to 74 groups, construct validity of the Questionnaire of Group Emotional Intelligence (OIEG) was tested, by means of a Principal Component Analysis (PCA). The results showed the emergency of four interpretable dimensions, instead of the five expected from the original scale. The dimensions evaluated in the OIEG - Group Regulation of Members, Group SelfAwareness, Group Self-Regulation, and Group Social Awareness/Skills - showed values of satisfactory internal consistency, indicating a good level of instrument's reliability.

KEY-WORDS: Group Emotional Intelligence, groups/teams, measure, principal component analysis. 